\title{
EARLY OUTCOMES OF MITRAL VALVE REPLACEMENT WITH A MECHANICAL PROSTHESIS FOR RHEUMATIC MITRAL VALVE DISEASE.
}

\footnotetext{
1. MBBS, MCPS, FCPS (Gen Surg), FCPS (Card Surg)

Assistant Professor Cardiac Surgery Rawalpindi Institute of Cardiology, Rawalpindi.

2. MBBS, FCPS (Cardiac Surgery), FEBCTS (Adult Cardiac Surgery), MEBCTS, MRCPS (Glasgow) Consultant Cardiac Surgeon Al Mana General Hospital, Al Khobar, Saudi Arabia.

3. MBBS, FCPS

Senior Registrar Cardiac Anesthesia Rawalpindi Institute of Cardiology, Rawalpindi

4. FCPS (Anesthesia),

FCPS (Cardiac Anesthesia)

Associate Professor Anesthesia

ACC, Lahore

5. MBBS, FCPS (Anesthesia) Assistant Professor Anesthesia Rawalpindi Institute of Cardiology, Rawalpindi
}

Correspondence Address: Dr. Musfireh Siddiqeh

Department of Cardiac Surgery Rawalpindi Institute of Cardiology, Rawalpindi.

musfirehsiddiqeh@gmail.com

Article received on:

04/07/2020

Accepted for publication:

$15 / 09 / 2020$
Musfireh Siddiqeh', Imran Khan ${ }^{2}$, Zainab Farid ${ }^{3}$, Fakhar e Fayyaz ${ }^{4}$, Qudsia Anjum ${ }^{5}$

ABSTRACT... Objectives: To study the early outcomes of mitral valve replacement with a mechanical prosthesis is patients with rheumatic mitral valvular disease. Study Design: Retrospective Observational study. Setting: Punjab Institute of Cardiology, Lahore and Rawalpindi Institute of Cardiology, Rawalpindi. Period: From August 2014 to August 2017. Material \& Methods: Consecutive patients who underwent mitral valve replacement for a rheumatic pathology were included in the study. Patients undergoing a redo surgery, those with concomitant aortic valve intervention, coronary artery bypass grafting and emergency procedures were excluded from the study. Results: Of the 104 patients included in the study, 58 $(56.2 \%)$ were female patients. The mean age of the patients was $35 \pm 12.36$ years (median 33 years). Sixty (58.5\%) had hypertension and $22(21.28 \%)$ had diabetes. Mitral valve stenosis was the main pathology in 84 (80.7\%). Severe pulmonary hypertension was recorded in $16(15 \%)$ patients. The mean preoperative Tricuspid Valve Pressure Gradient (TVPG) was $55.33 \pm 18.35$ $\mathrm{mmHg}$. The mean cross clamp time was $45.33 \pm 12.32$ minutes. The postoperative tricuspid valve pressure gradient came down to $31.5 \pm 12.21 \mathrm{mmHg}$. No patients had acute renal injury, pulmonary complications or re-exploration for bleeding. Perioperative mortality was 4 (3.75\%). Conclusion: Rheumatic valvular disease is still prevalent in our part of the world. Most of the patients with rheumatic heart disease will end up with replacement of the valve. Replacement with a mechanical prosthesis has favorable early outcomes.

Key words: $\quad$ In- Hospital Outcomes, Mechanical Prosthesis, Mitral Valve Replacement, Rheumatic Valve Pathology.

Article Citation: Siddiqeh M, Khan I, Farid Z, Fakhar e Fayyaz, Anjum Q. Early outcomes of mitral valve replacement with a mechanical prosthesis for rheumatic mitral valve disease. Professional Med J 2020; 27(10):2266-2270.

DOI: 10.29309/TPMJ/2020.27.10.5888

\section{INTRODUCTION}

Rheumatic fever is still an important cause of mitral valvular disease in the developing world. ${ }^{1}$ The culprit is group A $\beta$-hemolytic streptococci that can cause pharyngeal or cutaneous infection. The immune response of the body causes acute inflammation in various organs including the heart valves. ${ }^{2}$ The delayed response in adults is inflammation and scarring of the valvular apparatus. Approximately $60 \%$ patients who develop rheumatic fever will develop rheumatic heart disease. ${ }^{3}$

Mitral valve replacement with a mechanical or bioprosthetic prosthesis and mitral valve repair are the invasive options for mitral valvular disease in suitable patients. Recently, transcatheter technology has enabled MVR with a minimally invasive approach especially in high risk patients but this has not been studied well in rheumatic pathology. Secondly because of the cost issue, this has not achieved widespread acceptability in the developing world.

Rheumatic valvular disease has a different pathological course than degenerative pathologies and so the consequences are also different. ${ }^{4}$ Rheumatic disease causes the valve to get thickened, retracted and leads to severe commissural fusion. The subvalvular apparatus including the chordae and the papillary muscles also become thickened and retracted causing the leaflets to retract. Because of this extensive pattern of the disease, the valve is not always 
reparable. For this reason, mitral valve repair is not as successful as repair in degenerative pathologies. Moreover, because the disease affects the younger age group, most patients end up with a mechanical valve. Although free of degeneration, mechanical valve comes at the cost of increased bleeding due to anticoagulant use and thrombo-embolism. ${ }^{5}$

Rheumatic heart disease is still a major public health issue in a developing country like Pakistan. The bulk of the mitral valve surgeries performed annually are for rheumatic valvular disase6. Because of the pathological course as well as the younger demographics of the country, most of the patients require mitral valve replacement with mechanical prosthesis. Our study investigates the early outcomes of MVR in terms of the major morbidity indicator as well as mortality.

\section{MATERIAL \& METHODS}

Aretrospectiveobservational study was conducted at a tertiary care hospital from August 2014 to August 2017. The institutional ethical review board approved the study and individual consent was waivered considering the retrospective noninterventional nature of the study.

All the consecutive patients who underwent mechanical mitral valve replacement for rheumatic mitral valvular disease were included in the study. Patients who underwent urgent procedures, concomitant procedures like aortic valve replacement and coronary artery bypass grafting, those with pre-existing comorbidities and those who underwent mitral valve replacement with bioprosthetic prosthesis were excluded from the study. Also excluded were those undergoing a redo procedure and those who had any type of repair procedure through a left anterior thoracotomy.

All the patients were operated by the same surgical team lead by the same surgeon (MS). Standard operative techniques included median sternotomy, cannulation of the ascending aorta, bicaval cannulation and cardiopulmonary bypass in all the patients. The mitral valve was approached through the left atrium posterior to the interatrial sulcus. All the patients had rheumatic valvular disease. Clot in the left atrium, if present was evacuated first with closure of the left atrial appendage. All the patients were in sinus rhythm preoperatively so no procedure for atrial fibrillation was done. The valve was assessed for repair and preservation of the subvalvular apparatus. The subvalvular apparatus was preserved by debulking the mitral leaflets and then sewing the chordae to the annulus along with the valve sewing ring. An interrupted pledgeted technique was used for all the patients. Valve sizing was done only after placing all the sutures. The appropriate size valve was placed.

The data was analyzed using Statistical Package for Social Sciences version 23.0 (SPSS Inc., Chicago, IL, USA). Categorical variables were presented as frequencies and mean, median and standard deviations were calculated for continuous variables.

\section{RESULTS}

The study included 104 patients that included $58(56.2 \%)$ female patients. The mean age of the patients was $35 \pm 12.36$ years (median 33 years). In spite of this younger population, 60 (58.5\%) had hypertension and $22(21.28 \%)$ had diabetes. Mitral valve stenosis was the commonest pathology; 84 (81.25\%). Most of the patients, 60 (57.5\%) had moderate pulmonary hypertension while severe pulmonary hypertension was recorded in 15 (15\%) patients. The mean preoperative Tricuspid Valve Pressure Gradient (TVPG) was $55.33 \pm$ $18.35 \mathrm{mmHg}$. Moderate dyspnea as assessed by NYHA class II-III was present in 68 (65.5\%) patients. Preoperative left atrial size was 59.94 $\pm 11.43 \mathrm{~mm}$. other baseline characteristics are presented in Table-I.

Intraoperatively, all the patients underwent mitral valve replacement with mechanical prosthesis. All the patients had rheumatic pathology. The sub-valvular apparatus was preserved whenever possible. The mean cross clamp time was 45.33 \pm 12.32 minutes. Tricuspid valve repair with a modified DeVaga's procedure was done in 15 (15\%) patients. The postoperative tricuspid valve pressure gradient came down to $31.5 \pm$ 
$12.21 \mathrm{mmHg}$. No patients had acute renal injury, pulmonary complications or re-exploration for bleeding. Severe tricuspid valve regurgitation was recorded in $3(2.5 \%)$ patients. Perioperative mortality was 4 (3.75\%). Table-II.

\begin{tabular}{|c|c|c|c|}
\hline \multicolumn{3}{|c|}{ Variable } & Patients $(n=104)$ \\
\hline \multirow{2}{*}{ Gender } & \multicolumn{2}{|c|}{ Male } & $46(43.8 \%)$ \\
\hline & \multicolumn{2}{|c|}{ Female } & $58(56.2 \%)$ \\
\hline \multicolumn{3}{|l|}{ Age (Years) } & $35 \pm 12.36$ \\
\hline \multicolumn{3}{|l|}{ Diabetes } & $22(21.28 \%)$ \\
\hline \multicolumn{3}{|l|}{ Hypertension } & $60(58.5 \%)$ \\
\hline \multirow{3}{*}{$\begin{array}{l}\text { Primary mitral } \\
\text { valve pathology }\end{array}$} & \multicolumn{2}{|c|}{ Mitral stenosis } & $84(80.7 \%)$ \\
\hline & \multicolumn{2}{|c|}{$\begin{array}{l}\text { Mitral } \\
\text { regurgitation }\end{array}$} & $7(6.7 \%)$ \\
\hline & \multicolumn{2}{|c|}{ Mixed disease } & $9(8.7 \%)$ \\
\hline \multirow{3}{*}{$\begin{array}{l}\text { Pulmonary } \\
\text { arterial } \\
\text { hypertension }\end{array}$} & \multicolumn{2}{|c|}{ Mild } & $28(27.5 \%)$ \\
\hline & \multicolumn{2}{|c|}{ Moderate } & $60(57.5 \%)$ \\
\hline & \multicolumn{2}{|c|}{ Severe } & $16(15 \%)$ \\
\hline \multirow{3}{*}{ NYHA class } & \multicolumn{2}{|c|}{ Class I } & $23(22.5 \%)$ \\
\hline & \multicolumn{2}{|c|}{ Class II-III } & $68(65.5 \%)$ \\
\hline & \multicolumn{2}{|c|}{ Class IV } & $12(12.2 \%)$ \\
\hline \multicolumn{3}{|c|}{ Preoperative left atrial size (mm) } & $59.94 \pm 11.43$ \\
\hline \multicolumn{3}{|c|}{ Preoperative LVIDD (mm) } & $55.28 \pm 12.45$ \\
\hline \multicolumn{3}{|c|}{ Preoperative LVIDS (mm) } & $38.32 \pm 7.21$ \\
\hline \multicolumn{3}{|c|}{$\begin{array}{l}\text { Preoperative Tricuspid Valve } \\
\text { Pressure Gradient (TVPG) mmHg }\end{array}$} & $55.33 \pm 18.35$ \\
\hline \multicolumn{3}{|c|}{ Preoperative Ejection Fraction (\%) } & $55.23 \pm 6.4$ \\
\hline \multicolumn{4}{|c|}{ Table-I. Baseline characteristics of the patients. } \\
\hline \multicolumn{3}{|c|}{ Variable } & $\begin{array}{l}\text { Patients } \\
(n=80)\end{array}$ \\
\hline \multicolumn{3}{|c|}{ Bypass time (minutes) } & $75.64 \pm 15.55$ \\
\hline \multicolumn{3}{|c|}{ Cross clamp time (minutes) } & $45.33 \pm 12.32$ \\
\hline \multicolumn{3}{|c|}{$\begin{array}{l}\text { Tricuspid valve repair } \\
\text { (Modified Devaga's procedure) }\end{array}$} & $15(15 \%)$ \\
\hline \multicolumn{3}{|c|}{ ICU stay in days (median) } & 3 days \\
\hline Re-exploration fo & leed & & $0(0 \%)$ \\
\hline Pulmonary comp & ation & & $0(0 \%)$ \\
\hline Acute renal injur & & & $0(0 \%)$ \\
\hline $\begin{array}{l}\text { Postoperative Tri } \\
\text { Pressure Gradier }\end{array}$ & & $\mathrm{mHg}$ & $31.5 \pm 12.21$ \\
\hline & & Mild & $67(65 \%)$ \\
\hline Postoperative tric & & Moderate & $34(32.5 \%)$ \\
\hline & & Severe & $3(2.5 \%)$ \\
\hline Mortality & & & $4(3.75 \%)$ \\
\hline Table-II. Intrao & & $\begin{array}{l}\text { ad Postope } \\
\text { ables. }\end{array}$ & erative outcome \\
\hline
\end{tabular}

Professional Med J 2020;27(10):2266-2270.

\section{DISCUSSION}

This study sheds light on the cotemporary inhospital outcomes of mechanical mitral valve replacement for rheumatic heart disease. The long-term effect of rheumatic fever on the heart valves is chronic scarring and inflammation. Mitral valve is the most commonly involved valve. The scarring leads to mitral stenosis in most cases. Attempts to repair may not always be successful and the long-term results are inconsistent because of the extensive fibrosis in the valve leaflets and subvalvular apparatus. ${ }^{7}$

An important feature of the study is the younger age of our patients. This can be attributed to the fact that rheumatic fever affects children and young adults and the delayed effect on the heart valves appears mostly in the second and third decade of life. Butt and colleagues conducted a cross sectional survey of the patients with rheumatic heart disease undergoing surgery. ${ }^{8}$ The mean age of the patients in their study was 32.79 \pm 13.06 years demonstrating the younger age of the patients with rheumatic heart disease in this part of the world. This is in contrast to the studies published in the western literature. Myllykanga and colleagues conducted a population-based study about the trends of mitral valve surgery in Finland. ${ }^{9}$ They reported a mean age of 68 years in their cohort.

Although a younger age group, our cohort still included $21.28 \%$ diabetic patients. It has been seen that increasing numbers of diabetic patients are undergoing mitral valve replacement. In a study by Andres and colleagues from Spain, the prevalence of diabetes increased from $13.4 \%$ to $16.06 \%$ over a 15 years period. ${ }^{10}$ The presence of diabetes did not lead to unfavorable outcomes compared to patients with mechanical mitral valve replacement who did not have diabetes. In a single center study of 2964 patients at Emory hospital, Halkos and colleagues concluded that diabetes is associated with poor longterm survival in patients undergoing heart valve surgery. ${ }^{11}$ The mean age of the diabetic patients in their study was $62.4 \pm 12.4$ years while the same in our cohort was $34.9 \pm 15.06$ years. It is clear that the mean age of our patients is lower 
compared to most of the studied reported in the western literature. It would be interesting to see the long-term results of our patients with diabetes and mechanical mitral valve replacement.

More than 2/3 of our patients had moderate to severe pulmonary hypertension. But as evident from the falling tricuspid valve pressure gradient valve, most patients had a significant decrease in the TVPG and hence pulmonary artery pressure. This showed that the pulmonary artery pressure was secondary to the left sided valvular diseaseand responded well to replacement of the mitral valve. Lafci and colleagues measured the pulmonary artery pressures before and after mitral valve replacement in their cohort of 50 patients. ${ }^{12}$ They demonstrated significant decrease in pulmonary artery pressures after the valve replacement especially in those with preoperative pressure of more than $50 \mathrm{mmHg}$. Tempe and colleagues reported similar results after mechanical mitral valve replacement. ${ }^{13}$ It must be emphasized here that the degree of pulmonary hypertension does not strongly correlate with short term outcomes although it affects long term survival. This effect was demonstrated by Yang and colleagues in their observational study of 317 patients. ${ }^{14}$ They showed that although the 30-day mortality in patients with moderate to severe pulmonary hypertension is twice compared to patients with normal to mild pulmonary pressures, the intraoperative mortality is not significantly high.

Mitral valve replacement generally carries higher mortality compared to aortic valve replacement. Various studies have shown a mortality rate from $4 \%$ to $8 \% .{ }^{15,16}$ Advanced age, preoperative low ejection fraction, mitral regurgitation and advanced pulmonary hypertension have been identified as some of the predictors of perioperative mortality in these patients. ${ }^{17}$ The in-hospital mortality in our cohort was $3.75 \%$ which is comparatively lower than that reported in the literature. The reason for this low mortality can be the younger, fitter demographic profile of our patients as well as comparatively lower percentage of patients with advanced pulmonary hypertension. Another factor may be the low percentage of patients with mitral regurgitation (7.3\%).
A retrospective single center experience is an important limitation of our study. For this reason, generalizability to other patient groups should be done with caution. Secondly, we did not include a control group to compare the results. It would be interesting to see the outcome in the presence of a properly matched control group. Nonetheless, our study presents the real-world results of mitral valve replacement with mechanical valve in patients with rheumatic valvular pathology in our population. Large scale studies in this context will shed more light on the outcome of surgery for this disease which is so prevalent in this part of the world.

\section{CONCLUSION}

Rheumatic heart disease is still very common in our part of the world. Most of the patients presented to our setup ended up with mitral valve replacement for rheumatic mitral valve diseases with acceptable early outcomes.

\section{Copyright $@ 15$ Sep, 2020.}

\section{REFERENCES}

1. Harb SC, Griffin BP. Mitral valve disease: A comprehensive review. Curr Cardiol Rep. 2017; 19(8):73. doi:10.1007/s11886-017-0883-5.

2. Zakkar M, Amirak E, Chan KM, Punjabi PP. Rheumatic mitral valve disease: Current surgical status. Prog Cardiovasc Dis. 2009; 51(6):478-481. doi: 10.1016/j. pcad.2008.08.008.

3. Carapetis JR, Currie BJ, Mathews JD. Cumulative incidence of rheumatic fever in an endemic region: a guide to the susceptibility of the population?. Epidemiology \& Infection. 2000 Apr;124(2):239-44.

4. lung B, Vahanian A. Epidemiology of valvular heart disease in the adult. Nat Rev Cardiol. 2011; 8(3):162172. doi:10.1038/nrcardio.2010.202.

5. Misawa Y. Valve-related complications after mechanical heart valve implantation. Surg Today. 2015; 45(10):1205-1209. doi:10.1007/s00595-014-11040 .

6. Ahmad M, Janjuja AM, Iqbal MA. Mitral valve repair in a rheumatic population: an experience at AFIC/ NIHD. Pakistan Armed Forces Medical Journal. 2017 Feb 28;67(1):150-54. 
7. van derMerwe J, Casselman F. Mitral valve replacementcurrent and future perspectives. Open J Cardiovasc Surg. 2017; 9:1179065217719023. Published 2017 Jul 13. doi:10.1177/1179065217719023.

8. Butt HI, Shahbaz A, Nawaz H, Butt K. Comparative clinical characteristics of rheumatic heart disease patients undergoing surgical valve replacement. Cureus. 2019 Jun; 11(6): e4889. DOI: 10.7759/ cureus.4889.

9. Myllykangas ME, Aittokallio JM, Pietilä A, Salomaa VV, Gunn JM, Kiviniemi TO, et al. Population trends in mitral valve surgery in Finland between 1997 and 2014: The finish CVD register. Scand Cardiovasc J. 2018; 52:51-7.

10. López-de-Andrés A, de Miguel-Díez J, Muñoz-Rivas $\mathrm{N}$, et al. Impact of type 2 diabetes mellitus in the utilization and in-hospital outcomes of surgical mitral valve replacement in Spain (2001-2015). Cardiovasc Diabetol. 2019; 18(1):60. Published 2019 May 10. doi:10.1186/s12933-019-0866-5.

11. Halkos ME, Kilgo $P$, Lattouf $O M$, et al. The effect of diabetes mellitus on in-hospital and longterm outcomes after heart valve operations. Ann Thorac Surg. 2010; 90(1):124-130. doi: 10.1016/j. athoracsur.2010.03.111.

12. Lafçı G, Diken Al, Gedik HS, et al. Mitral kapak değişimi sonrası pulmoner arter basıncındaki değişiklikler [Alterations in pulmonary artery pressure following mitral valve replacement]. Turk Kardiyol Dern Ars. 2012; 40(3):235-241. doi:10.5543/tkda.2012.02328.
13. Tempe DK, Hasija S, Datt V, et al. Evaluation and comparison of early hemodynamic changes after elective mitral valve replacement in patients with severe and mild pulmonary arterial hypertension. $J$ Cardiothorac Vasc Anesth. 2009; 23(3):298-305. doi: 10.1053/j.jvca.2009.01.011.

14. Yang B, DeBenedictus $C$, Watt $T$, et al. The impact of concomitant pulmonary hypertension on early and late outcomes following surgery for mitral stenosis [published correction appears in $\mathrm{J}$ Thorac Cardiovasc Surg. 2016 Nov; 152(5):1465]. J Thorac Cardiovasc Surg. 2016; 152(2):394-400.e1. doi: 10.1016/j. jtcvs.2016.02.038.

15. Chikwe J, Chiang YP, Egorova NN, Itagaki S, Adams $\mathrm{DH}$. Survival and outcomes following bioprosthetic vs mechanical mitral valve replacement in patients aged 50 to 69 years. JAMA. 2015; 313(14):1435-1442. doi:10.1001/jama. 2015.3164.

16. Bakaeen FG, Shroyer AL, Zenati MA, Badhwar V, Thourani VH, Gammie JS, et al. Mitral valve surgery in the US veteran's administration health system: 10year outcomes and trends. J Thorac Cardiovasc Surg. 2018; 155(105-117):e5.

17. De-Miguel-Díez J, López-de-Andrés A, HernándezBarrera V, et al. Trends, characteristics, in-hospital outcomes and mortality in surgical mitral valve replacement among patients with and without COPD in Spain (2001-2015). PLoS One. 2019; 14(8): e0221263. Published 2019 Aug 19. doi: 10.1371/journal. pone.0221263.

\begin{tabular}{|c|c|c|c|}
\hline \multicolumn{4}{|c|}{ AUTHORSHIP AND CONTRIBUTION DECLARATION } \\
\hline Sr. \# & Author(s) Full Name & Contribution to the paper & Author(s) Signature \\
\hline 1 & Musfireh Siddiqeh & $\begin{array}{l}\text { Concept, Background, Data } \\
\text { collection. }\end{array}$ & \\
\hline 2 & Imran Khan & $\begin{array}{l}\text { Writing up, Statistical } \\
\text { analysis. }\end{array}$ & \\
\hline 3 & Zainab Farid & Data collection. & \\
\hline 4 & Fakhar e Fayyaz & Data collection. & \\
\hline 5 & Qudsia Anjum & Write up. & \\
\hline
\end{tabular}

